\title{
Calogênese em Cissus sicyoides L. a partir de segmentos foliares visando à produção de metabólitos in vitro
}

RODRIGUES, F.R. *; ALMEIDA, W.A.B.

Universidade Federal do Recôncavo da Bahia, CEP: 44380-000, Cruz das Almas-Brasil ‘fabyolasr@hotmail.com

\begin{abstract}
RESUMO: Os metabólitos secundários são essencialmente produzidos e extraídos a partir de plantas cultivadas no campo sobre a influência de variações sazonais. A utilização de técnicas biotecnológicas apresenta-se como um recurso alternativo para a produção de fármacos. Dentre essas técnicas, destaca-se a cultura de tecidos através da calogênese, uma vez que o crescimento de calos é desejável para induzir variação somaclonal e estudos fisiológicos, principalmente quando se deseja relacionar a presença de metabólitos secundários com o crescimento celular. Assim, o objetivo deste trabalho foi estabelecer um protocolo de calogênese de Cissus sicyoides L., a partir de segmentos foliares visando à produção de metabólitos in vitro. Para o estabelecimento in vitro, foram utilizados como explantes, segmentos foliares retirados de planta adulta cultivada em campo. Após desinfestação, o material foi inoculado em meio $\mathrm{MT}+1,0 \mathrm{mg} \mathrm{L}^{-1}$ ANA e mantido em câmara de crescimento tipo BOD, com temperatura e luminosidade controladas. Após 30 dias foram avaliados a porcentagem de explantes sobreviventes e de contaminação. Para o cultivo utilizou-se o meio MT + 1,0 $\mathrm{mg} \mathrm{L}^{-1}$ ANA, variando-se as concentrações de BAP em 2,0; 4,$0 ; 6,0$ e 12,0 $\mathrm{mg} \mathrm{L}^{-1}$. No cultivo avaliou-se o número de calos compactos e friáveis. Para o primeiro e segundo subcultivo o material foi introduzido em meio $\mathrm{MT}+1,0 \mathrm{mg} \mathrm{L}^{-1}$ ANA variandose as mesmas concentrações de BAP, sendo avaliados o número de calos friáveis formados e 0 tamanho da massa de calos. Foi obtido ainda o número de repetições formadas no decorrer dos subcultivos, peso da matéria fresca $(\mathrm{g})$ e seca $(\mathrm{g})$. Em seguida, foram realizados os testes fitoquímicos para identificação de alguns constituintes. Concluiu-se que o tempo e a concentração de hipoclorito de sódio utilizado, mostraram-se pouco eficientes para a desinfestação. Para a calogênese de Cissus sicyoides $L$. a partir de segmento foliar faz-se necessário a adição de 6,0 $\mathrm{mg} \mathrm{L}^{-1}$ de BAP ao meio de cultivo. Identificou-se a presença de heterosídeos cardiotônicos em calos de Cissus sicyoides L.
\end{abstract}

Palavras-chave: metabólitos secundários, explante, cultivo

\begin{abstract}
Calluses from Cissus sicyoides L. leaves. Secondary metabolites are essentially produced and extracted from plants grown in the field under influence of seasonal variations. The use of biotechnological techniques is an alternative resource for drug production. Among these techniques, tissue culture through callus genesis is highlighted, since callus growth is desirable to induce somaclonal variation and physiological studies, especially when the presence of secondary metabolites can be related to cell growth. The aim of this work was to establish a protocol for Cissus sicyoides $\mathrm{L}$. callus genesis from leaf segments in order to produce metabolites in vitro. Thus, leaf segments removed from adult plants grown in the field were used as explants. After disinfestation, the material was inoculated into MT medium $+1.0 \mathrm{mg} \mathrm{L}^{-1} \mathrm{NAA}$ and kept in a BOD chamber, with controlled temperature and luminosity. After 30 days, the percentage of surviving explants and the percentage of contamination were evaluated. For culture, MT medium $+1.0 \mathrm{mg}$ $\mathrm{L}^{-1} \mathrm{NAA}$ was used, varying BAP concentrations: $2.0,4.0,6.0$ and $12.0 \mathrm{mg} \mathrm{L}^{-1}$. In the cultivation, the number of compact and friable calluses was counted. For the first and second subculture, the material was introduced into MT medium $+1.0 \mathrm{mg} \mathrm{L}^{-1} \mathrm{NAA}$, varying the same BAP concentrations; the number of friable calluses formed and the size of callus mass were described. The number of replicates formed during subcultures, and fresh and dry matter $(\mathrm{g})$ were also obtained. Then, phytochemical tests were done in order to identify some compounds. The adopted time and
\end{abstract}

Recebido para publicação em 28/08/2009

Aceito para publicação em 30/04/2010

Rev. Bras. Pl. Med., Botucatu, v.12, n.3, p.333-340, 2010. 
concentration of sodium hypochlorite proved to be inefficient for disinfestation. For Cissus sicyoides $\mathrm{L}$. callus genesis from leaf segments, the addition of $6.0 \mathrm{mg} \mathrm{L}^{-1}$ BAP to the culture medium is needed. Cardiotonic heterosides were detected in Cissus sicyoides L. calluses.

Key words: secondary metabolites, explants, culture

\section{INTRODUÇÃO}

O gênero Cissus é o maior da família Vitaceae, com cerca de 350 espécies distribuídas entre as Américas, à Ásia e a Austrália. Estudos realizados com algumas espécies de Cissus têm revelado várias atividades farmacológicas, dentre as quais antioxidante e antimicrobiana (Murthy et al., 2004; Silva et al., 2007), inibidor da enzima acetilcolinesterase (Barbosa-Filho et al., 2006) e hipoglicemiante (Barbosa et al., 2002).

Alguns esteróides presentes na natureza caracterizam-se pela grande especificidade pelo miocárdio e poderosa ação que exercem sobre este. Esses esteróides ocorrem como glicosídeos com açúcares ligados na posição 3 do núcleo esteroidal (Simões et al., 2004). Conforme estes autores, devido à ação sobre o miocárdio, chamam-se glicosídeos ou heterosídeos cardiotônicos. Alguns metabólitos já foram identificados em Cissus sicyoides L., tais como alcalóides e flavonóides além de saponinas, mucilagens e compostos fenólicos (Silva, 1995).

O estudo da propagação de espécies utilizadas na medicina popular tem sido intensificado nos últimos anos, devido ao crescente investimento em pesquisas para a descoberta de novos fármacos e da utilização da fitoterapia como meio alternativo. Em plantas medicinais, a cultura de tecidos tem auxiliado na propagação clonal de diversos genótipos, permitindo a conservação do germoplasma; a obtenção de novas fontes de variabilidade através do cultivo de calos e células; na engenharia genética e na otimização da produção de metabólitos (Botta et al., 2001; Rao \& Ravishankar, 2002; Arikat, 2004). O crescimento de calos é desejável para induzir variação somaclonal e estudos fisiológicos, principalmente quando se deseja relacionar a presença de metabólitos secundários com o crescimento celular.

Diversos fatores interferem na calogênese, tais com o tamanho do explante, composição do meio de cultura, reguladores vegetais, órgão fornecedor do explante, idade e época do ano em que o explante é colhido e genótipo da planta doadora (Cerqueira et al., 2002). Calos podem ser multiplicados por sucessivas subculturas, mantidos in vitro por longos períodos e são de grande importância para estudos morfogenéticos in vitro e através da suspensão de células para a obtenção de produtos secundários, incluindo fármacos, representando uma biotecnologia de grande interesse científico e comercial. Assim, o objetivo deste trabalho foi estabelecer protocolo de calogênese de Cissus sicyoides L. a partir de segmentos foliares visando a produção de metabólitos in vitro.

\section{MATERIAL E METÓDO}

O experimento foi conduzido no Laboratório de Cultura de Tecidos de Plantas, do Centro de Ciências Agrárias, Ambientais e Biológicas da Universidade Federal do Recôncavo da Bahia, em parceria com o Laboratório de Biotecnologia da Faculdade Maria Milza (FAMAM).

Desinfestação do material: Utilizou-se como explantes, segmentos foliares de aproximadamente $1 \mathrm{~cm}^{2}$, que foram retirados de plantas adultas, oriundas em campo nativo do Município de Elísio Medrado, (1256'45"S e 39॰31'19'W) - Bahia. As folhas coletadas, foram lavadas em água corrente e desinfestadas em solução de álcool etílico na concentração de $70 \%$ durante 2 minutos, em seguida foram imersas em solução de hipoclorito de sódio comercial (Q'Boa 2,0 a 2,5\% de cloro ativo) e água na concentração de $2: 1$, durante 15 minutos em agitador magnético. O material vegetal foi lavado 3 vezes em câmara de fluxo laminar com água estéril.

Estabelecimento in vitro: Os segmentos foliares, foram inoculadas em placas de Petri contendo $20 \mathrm{~mL}$ meio de cultura MT (Murashige \& Tucker, 1969) sólido, suplementado com 1,0 $\mathrm{mg} \mathrm{L}^{-1}$ ANA (ácido naftalenoacético), $25 \mathrm{~g} \mathrm{~L}^{-1}$ sacarose e solidificado com fitagel $(0,2 \%)$, totalizando 10 placas de Petri contendo 5 explantes cada. $\mathrm{O} \mathrm{pH}$ do meio de cultura foi ajustado a 5.8, anteriormente à autoclavagem a $123^{\circ} \mathrm{C}$ por 20 minutos. O experimento foi conduzido em câmara de crescimento tipo BOD, com temperatura de $27 \pm 2^{\circ} \mathrm{C}$ e fotoperíodo de 16 horas e $40 \mu \mathrm{M} \mathrm{m}^{-2} \mathrm{~s}^{-1}$ de intensidade luminosa. Após 30 dias foram avaliados a porcentagem de explantes responsivos com calo e contaminação.

Cultivo in vitro: Após a indução de calos, procedeu-se o cultivo dos mesmos, em meio sólido MT $+1,0 \mathrm{mg} \mathrm{L}^{-1}$ ANA, variando-se as concentrações de BAP (6-benzilaminopurina) em: 2,0;4,0; 6,0 e 12,0 mg $\mathrm{L}^{-1}$. O material foi cultivado em frascos nas mesmas condições anteriormente citadas e decorridos 40 dias foram avaliados os números de calos compactos e friáveis obtidos.

Primeiro subcultivo: Os calos friáveis formados durante o cultivo foram utilizados como explantes para

Rev. Bras. PI. Med., Botucatu, v.12, n.3, p.333-340, 2010. 
esta fase. Utilizou-se o meio sólido $M T+1,0 \mathrm{mg} \mathrm{L}^{-1}$ ANA, fixando as concentrações de BAP (6benzilaminopurina) em: 2,0; 4,0; 6,0 e 12,0 $\mathrm{mg} \mathrm{L}^{-1}$. O material foi cultivado em placas de Petri nas mesmas condições anteriormente citadas e decorridos 40 dias foram avaliados o número de calos friáveis formados e a porcentagem de área coberta com calos. Na avaliação do tamanho da massa de calos, considerou-se que os explantes apresentavam 25, 50, 75 e 100\% da área coberta com calos, conforme Lameira et al. (1997).

Segundo Subcultivo: Os calos friáveis formados durante o primeiro subcultivo foram utilizados como explantes para esta fase. Semelhantemente ao primeiro subcultivo, utilizou-se o meio sólido MT + 1,0 mg L-1 ANA + 2,0; 4,0; 6,0 e 12,0 $\mathrm{mg} \mathrm{L}^{-1}$ de BAP. O material foi cultivado em placas de Petri nas mesmas condições anteriormente citadas e decorridos 40 dias foram avaliados o número de calos friáveis formados e tamanho da massa de calos, onde considerou-se que os explantes apresentavam 25, 50, 75 e $100 \%$ da área coberta com calos, conforme Lameira et al. (1997).

Testes Fitoquímicos: O número de repetições formadas por tratamento variou ao longo dos subcultivos. Para as avaliações referentes a matéria fresca, seca e a realização dos testes fitoquímicos, considerou-se 0 menor número de repetições formadas a partir do segundo subcultivo, ou seja, cinco repetições de cada tratamento. Após as avaliações do segundo subcultivo, fez-se as avaliações referentes ao peso da matéria fresca ( $g$ ) dos calos sendo estes posteriormente submetidos à secagem em estufa na temperatura de $38^{\circ} \mathrm{C}$, por 8 horas consecutivas, para obtenção da matéria seca $(\mathrm{g})$. Em seguida os calos foram transferidos para erlenmeyers e cobertos com álcool etílico para o início do processo de maturação. Durante três dias, os calos permaneceram em maturação, para obtenção do extrato etanólico, sendo manualmente agitados duas vezes ao dia. Decorrido este período o extrato etanólico foi filtrado e realizado os testes fitoquímicos (Tabela 1).

\section{Delineamento experimental}

- Cultivo: Delineamento utilizado foi o inteiramente casualizado, com 4 tratamentos e 4 repetições, sendo cada repetição constituída por um frasco com quatro calos. Os dados obtidos foram analisados estatisticamente e submetidos ao teste de Tukey, com nível de significância de 5\%.

- Primeiro subcultivo: Delineamento utilizado foi o inteiramente casualizado, com 4 tratamentos e 6 repetições, sendo cada repetição constituída por uma placa de Petri com seis calos. Os dados obtidos foram analisados estatisticamente e submetidos ao teste de Tukey, com nível de significância de 5\%.

- Segundo subcultivo: Delineamento utilizado foi o inteiramente casualizado, com 4 tratamentos e 5 repetições, sendo cada repetição constituída por uma placa de Petri com seis calos. Os dados obtidos foram analisados estatisticamente e submetidos ao teste de Tukey, com nível de significância de $5 \%$. Os resultados dos testes fitoquímicos foram demonstrados pela ausência (-) ou presença (+) de reação.

\section{RESULTADO E DISCUSSÃO}

\section{- Estabelecimento in vitro de segmento foliar de Cissus sicyoides L.}

O processo de desinfestação utilizado mostrou-se pouco eficiente no estabelecimento in vitro de segmentos foliares de Cissus sicyoides L. obtendo elevada porcentagem de contaminação, cerca de $92 \%$ (Tabela 2). Vários fatores podem ter influenciado para o alto índice obtido, tais como a idade da planta matriz doadora dos explantes, o estado fisiológico da mesma e as condições ambientais como umidade relativa do ar, pluviosidade, etc.

O período de coleta de explantes é o

TABELA1. Constituintes químicos analisados, conforme metodologia proposta por Simões, et al. (2004).

\begin{tabular}{c|c}
\hline Constituintes analisados & Metodologia utilizada \\
\hline Alcalóides & Reação de Dragendorf \\
\hline Haterosídeos Cardiotônicos & $\begin{array}{c}\text { Reação de Liebermann-Burchard } \\
\text { (núcleo esteroidal) } \\
\text { Reação de Baljet e Reação de Kedde } \\
\text { (Anel lactônico pentagonal) }\end{array}$ \\
\hline Taninos & Reação com $\mathrm{FeCl}_{3}$ \\
\hline Saponinas & Altura da espuma formada \\
\hline Flavonóides & Reação de Shinoda \\
\hline Derivados Andracênicos & Reação de Borntrager \\
\hline Cumarinas & Fluorescência no UV
\end{tabular}

Rev. Bras. Pl. Med., Botucatu, v.12, n.3, p.333-340, 2010. 
TABELA 2. Porcentagem de contaminação no estabelecimento in vitro de segmento foliar a partir de tecido adulto de Cissus sicyoides após trinta dias de cultivo.

\begin{tabular}{c|c|ccc|c}
\hline \multirow{2}{*}{$\begin{array}{c}\text { \% Explantes } \\
\text { sobreviventes }\end{array}$} & \multicolumn{3}{|c|}{ \% Explantes contaminados } & $\begin{array}{c}\text { Total de } \\
\text { explantes }\end{array}$ \\
\hline \multirow{2}{*}{8} & Fungo $(\mathrm{F})$ & Bactéria (B) & $\begin{array}{c}\text { Contaminação } \\
(\mathrm{F}+\mathrm{B})\end{array}$ & Total & \multirow{2}{*}{100} \\
\cline { 2 - 5 } & 18 & 22 & 52 & 92 & \\
\hline
\end{tabular}

${ }^{*} \mathrm{~F}+\mathrm{B}$ : Associação entre fungo e bactéria no mesmo explante.

principal fator limitante para o sucesso no estabelecimento in vitro, sendo na época chuvosa, maior a incidência de microorganismos (Costa et al., 2007). Estes mesmos autores, trabalhando no estabelecimento de alecrim pimenta (Lippia sidoides Cham.) a partir de explantes extraídos de planta adulta em casa de vegetação (segmentos nodais), concluíram que o aumento da concentração e tempo de imersão na desinfestação, tempos de 12 e 16 minutos, proporcionam menor porcentagem de contaminação. Os trabalhos de cultivo in vitro, na maioria, têm utilizado material juvenil como explante, em virtude do baixo nível de contaminação e do elevado potencial morfogenético (Barceló-Múñoz et al., 1999). Em geral, a indução de calos em $C$. sicyoides $L$. ocorreu entre a segunda e a terceira semana de inoculação (Figura 1B), iniciando o processo na borda dos discos. Para algumas variedades de citrus, em geral, a indução de calos ocorre entre a sexta e oitava semanas de cultivo em meio MT (Kayim \& Koc, 2006).

\section{- Cultivo de calos de Cissus sicyoides in vitro}

Observou-se a formação de calos que apresentaram consistência predominantemente compacta (Figura 2A) e friável (Figura 2B), com coloração variando entre verde e amarelo. A concentração de $4,0 \mathrm{mg} \mathrm{L}^{-1}$ de BAP, promoveu o maior número de calos compactos, média de 3,80 embora não diferindo significativamente das concentrações 2,0 e 6,0 $\mathrm{mg} \mathrm{L}^{-1}$, com médias de 3,0 e 2,4 calos compactos, respectivamente. O maior número de calos friáveis foi obtido utilizando-se $12,0 \mathrm{mg} \mathrm{L}^{-1}$ BAP, sendo que não houve diferença significativa desta concentração em relação às concentrações 2,0 e 6,0 $\mathrm{mg} \mathrm{L}^{-1}$ de BAP. Maior proliferação de calos friáveis foi obtida cultivando-se segmentos nodais de Pfaffia tuberosa, com $1 \mathrm{mM}$ de BAP e $10 \mathrm{mM}$ de 2,4-D em meio MS (Flores et al., 2006).

\section{- Primeiro subcultivo de calos de Cissus sicyoides}

Conforme a Figura 3 observou-se que o número de calos friáveis diminuiu com o aumento da concentração da citocinina, sendo na concentração
2,0 $\mathrm{mg} \mathrm{L}^{-1}$ BAP obtido o maior número de calos, cerca de 5,83 embora não diferindo significativamente das concentrações 4,0 e 6,0 mg L-1, com médias de 5,33 e 4,66, respectivamente.

No subcultivo dos calos de $C$. sicyoides, verificou-se que a concentração de $12,0 \mathrm{mg} \mathrm{L}^{-1}$ promoveu menor formação de calos (Figura 4). Nogueira et al. (2007) concluíram que não houve efeito positivo da utilização de BAP ou TDZ em interação com 2,4-D na calogênese em explantes foliares de murici-pequeno, uma planta utilizada como medicinal. O balanço hormonal obtido entre os níveis de citocininas e auxinas, exógenas e endógenas do calo, podem tanto estimular a proliferação celular como exercer um efeito antagônico, reduzindo a multiplicação dos mesmos.

Com relação ao tamanho da massa de calos, considerou-se que os explantes apresentavam $25,50,75$ e 100\% da área coberta com calos (Figura 5), segundo metodologia descrita por Lameira et al. (1997). Os resultados são apresentados na Tabela 3.

Entre os tratamentos utilizados, observouse que não houve diferença significativa para 0 número de explantes com diferentes porcentagens de cobertura com calo. Entretanto, a concentração de $6,0 \mathrm{mg} \mathrm{L}^{-1} \mathrm{BAP}$, foi aquela com maior número de explantes com $100 \%$ de área coberta com calos. No entanto, dentro da mesma concentração de BAP, verificou-se diferenças significativas, destacando-se as concentrações de 4,0 e 6,0 $\mathrm{mg} \mathrm{L}^{-1}$ de BAP, com maior número de explantes com $25 \%$ de área coberta com calos.

Cerqueira (1999), trabalhando na indução de calos em segmentos foliares de erva-de-touro (Tridax procumbens), obteve o melhor resultado quando se adicionou ao meio MS 2,0 $\mathrm{mg} \mathrm{L}^{-1}$ de ANA + $2,0 \mathrm{mg} \mathrm{L}^{-1}$ de BAP, resultando em $100 \%$ de área coberta com calos. A maioria dos tratamentos formaram calos friáveis, excetuando-se o tratamento com $12,0 \mathrm{mg} \mathrm{L}^{-1}$ de BAP, que formou calos de consistência pouco compacta. Notou-se também que à medida que foi aumentada a concentração de BAP, alguns calos mostraram início de necrose, sugerindo toxidez.

Rev. Bras. PI. Med., Botucatu, v.12, n.3, p.333-340, 2010. 


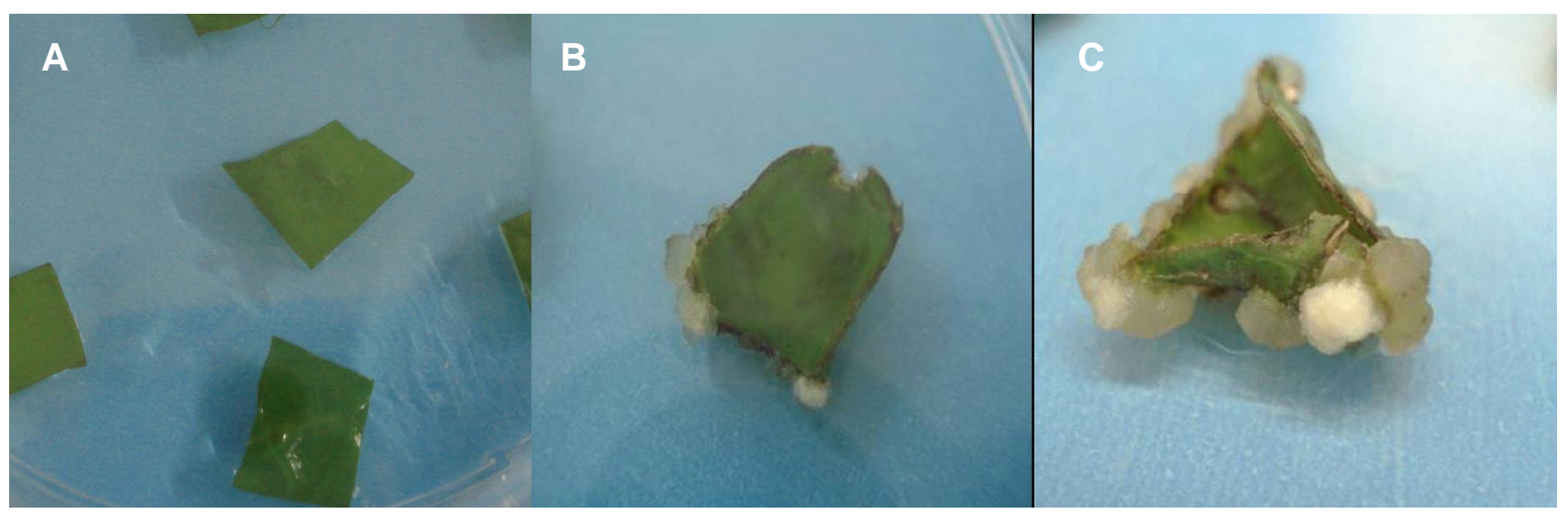

FIGURA 1. Estabelecimento in vitro de segmentos foliares a partir de tecido adulto de Cissus sicyoides L. ASegmentos foliares in vitro no primeiro dia de cultivo. B- Início da formação de calo, aos quinze dias de cultivo. CMargem do explante coberta por calo aos trinta dias de cultivo.

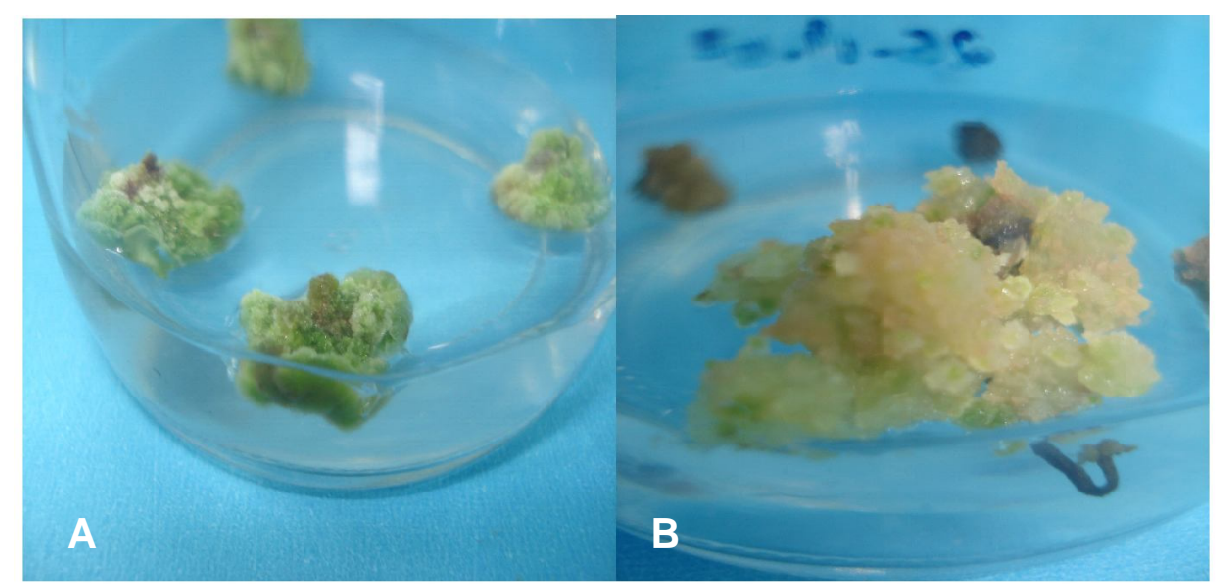

FIGURA 2. Calos de Cissus sicyoides L. in vitro aos quarenta dias de cultivo. A- Calos compactos. B- Calo friável.

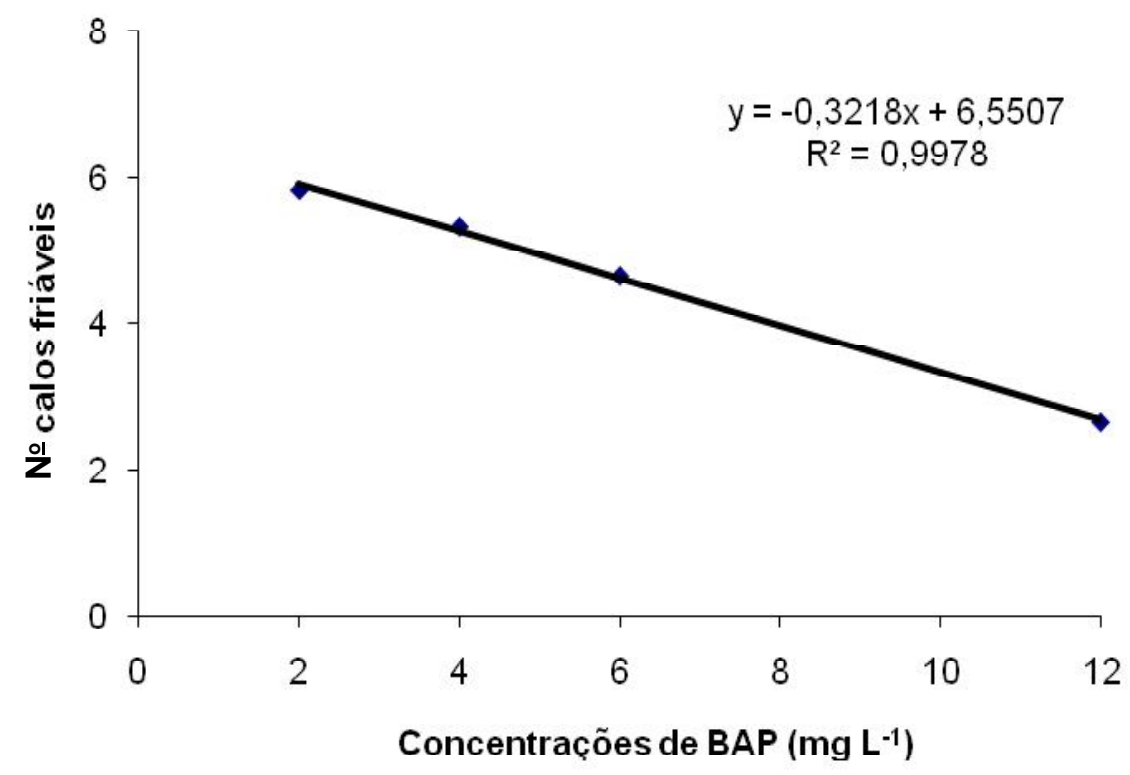

FIGURA 3. Número de calos friáveis obtidos a partir do primeiro subcultivo de calos de Cissus sicyoides L. em função diferentes concentrações de BAP. 


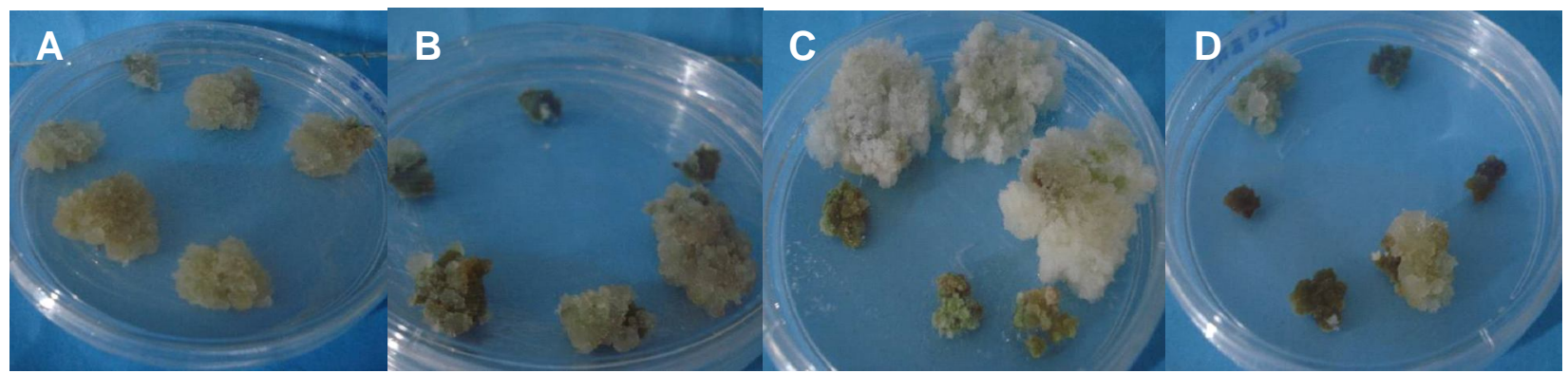

FIGURA 4. Primeiro subcultivo em calos de Cissus sicyoides L., a partir de segmentos foliares aos quarenta dias de cultivo. A- Tratamento 2,0 $\mathrm{mg} \mathrm{L}^{-1}$ BAP. B- Tratamento 4,0 $\mathrm{mg} \mathrm{L}^{-1}$ BAP. C- Tratamento 6,0 $\mathrm{mg} \mathrm{L}^{-1}$ BAP. DTratamento 12,0 $\mathrm{mg} \mathrm{L}^{-1} \mathrm{BAP}$, todos os tratamentos combinados com 1,0 $\mathrm{mg} \mathrm{L}^{-1}$ ANA.

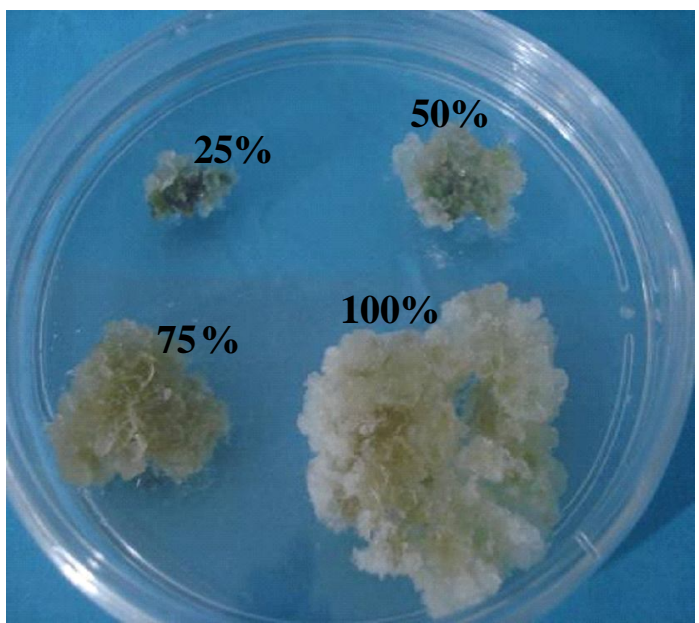

FIGURA5. Tamanho da massa de calos expressa pela porcentagem da área coberta com calos friáveis em Cissus sicyoides L. a partir do primeiro subcultivo.

\section{sicyoides}

- Segundo subcultivo de calos de Cissus

A partir do segundo subcultivo todas as concentrações de BAP formaram calos friáveis (Figura 6), não diferindo significativamente entre si. Com relação ao tamanho da massa de calos, observou-se que quando se adicionou ao meio a concentração de $6,0 \mathrm{mg} \mathrm{L}^{-1}$ de BAP, resultou em maior número de calos com $100 \%$ de área coberta, com media de 4,20, sendo diferente significativamente das demais concentrações.
Segundo Santos (1998), elevadas concentrações de citocinina parecem interagir com a quantidade de auxina endógena do explante, o que leva à formação de calos. A textura e morfologia do calo, manipulada pelas variações nos constituintes do meio nutritivo, produz calos macios, friáveis e úmidos, em meio de alta concentração de auxina e baixa de citocinina e se a relação é inversa, produz calos de tecido compacto seco e com células pequenas. Cordeiro et al. (2004) observaram baixa frequência de calos em Schizolobium amazonicum Huber ex Ducke (paricá) no meio de cultura sem regulador vegetal, porém observaram que à medida que se aumentou a concentração do regulador BAP, ocorreu maior incidência de calos endógenos. Segundo estes autores, isto aconteceu, provavelmente, devido ao desbalanceamento nos níveis endógenos de fitormônios nos explantes.

O número de repetições formadas por tratamento variou ao longo dos subcultivos. Para análise estatística, considerou-se para cada subcultivo, o menor número de repetições formadas. No entanto, o número de repetições formadas por tratamento no decorrer dos subcultivos foi considerada uma variável, sendo analisada separadamente (Figura 8).

Considerando a matéria fresca dos calos, verificou-se que as concentrações de BAP utilizadas não diferiram entre si. Com relação a matéria seca, observou-se que na concentração de $6,0 \mathrm{mg} \mathrm{L}^{-1} \mathrm{BAP}$

TABELA 3. Efeito de concentrações de BAP no número de explantes com diferentes porcentagens de cobertura de calo.

\begin{tabular}{c|cc|c|c}
\hline \multirow{2}{*}{$\begin{array}{c}\text { Concentrações de BAP } \\
\text { mg L }^{-1}\end{array}$} & \multicolumn{4}{c}{ \% Cobertura de calo } \\
\cline { 2 - 5 } & 25 & 50 & 75 & 100 \\
\hline 2 & $2,50 \mathrm{aA}$ & $1,33 \mathrm{aA}$ & $1,33 \mathrm{aA}$ & $0,66 \mathrm{aA}$ \\
4 & $4,16 \mathrm{aA}$ & $0,83 \mathrm{aB}$ & $1,66 \mathrm{aB}$ & $0,16 \mathrm{aB}$ \\
6 & $3,33 \mathrm{aA}$ & $0,33 \mathrm{aB}$ & $0,16 \mathrm{aB}$ & $1,00 \mathrm{aB}$ \\
12 & $2,16 \mathrm{aA}$ & $0,33 \mathrm{aB}$ & $0,16 \mathrm{aB}$ & $0,16 \mathrm{aB}$ \\
\hline
\end{tabular}

*Médias seguidas da mesma letra minúscula na vertical e maiúscula da horizontal não diferem significativamente $($ Tukey 0,05$)$.

Rev. Bras. PI. Med., Botucatu, v.12, n.3, p.333-340, 2010. 


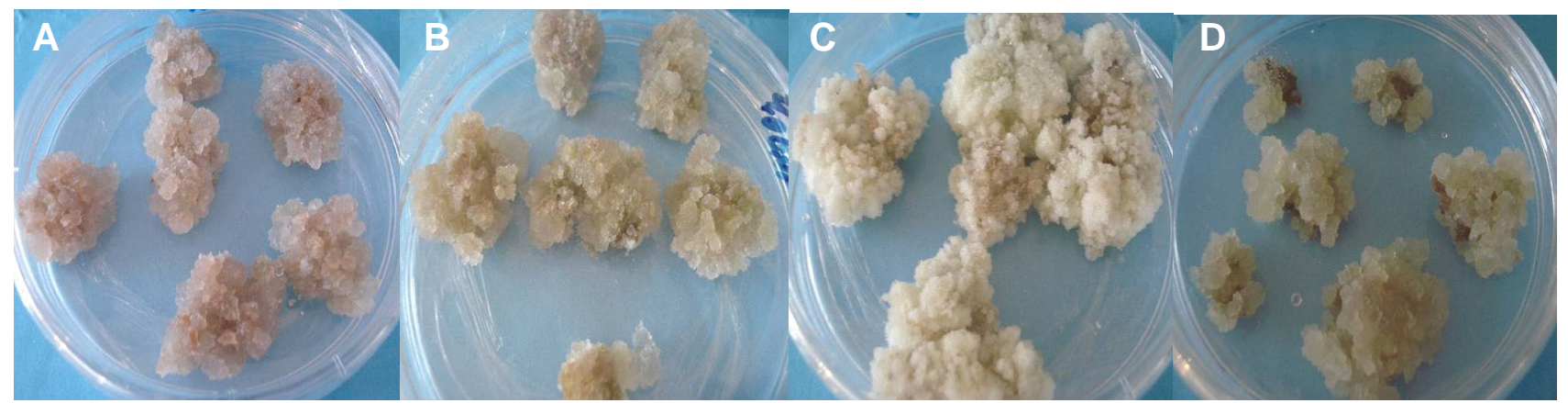

FIGURA 6. Segundo subcultivo em calos de Cissus sicyoides L., a partir de segmentos foliares aos quarenta dias de cultivo. A- Tratamento 2,0 $\mathrm{mg} \mathrm{L}^{-1}$ BAP. B- Tratamento 4,0 $\mathrm{mg} \mathrm{L}^{-1}$ de BAP. C- Tratamento 6,0 $\mathrm{mg} \mathrm{L}^{-1}$ de BAP. D- Tratamento $12,0 \mathrm{mg} \mathrm{L}^{-1}$ de BAP, todos os tratamentos combinados com 1,0 $\mathrm{mg} \mathrm{L}^{-1}$ de ANA.

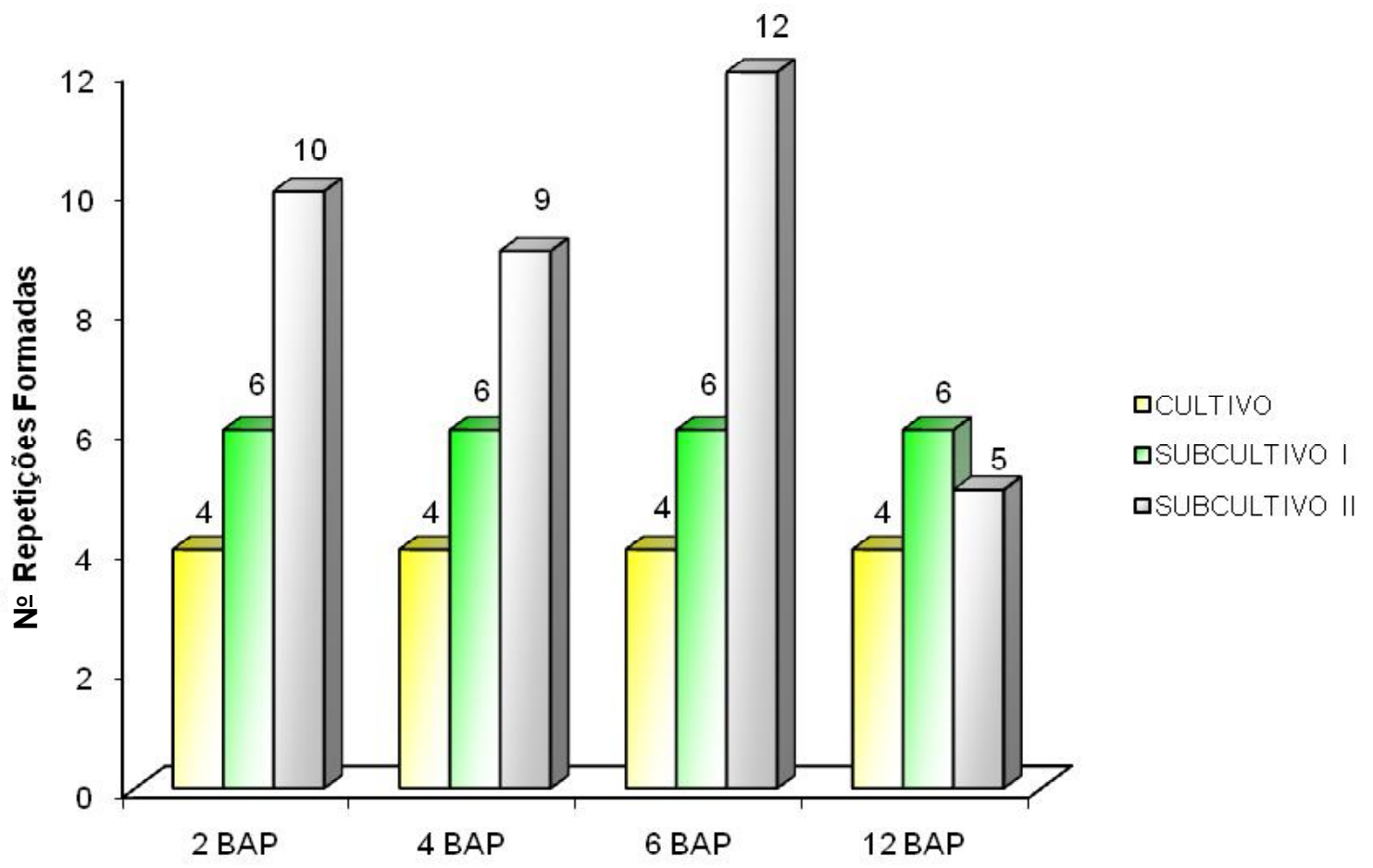

FIGURA 8. Número de repetições formadas na calogênese de Cissus sicyoides L. in vitro.

foi obtido a maior matéria seca de calos de $C$. sisyoides L., embora não diferindo significativamente das concentrações de 2,0 e 4,0 $\mathrm{mg} \mathrm{L}^{-1}$ BAP (Figura 9). Para Cerqueira et al. (2002) o melhor resultado para a matéria fresca dos calos formados em segmentos foliares de Tridax procumbens, foi obtido com ANA na concentração de $2,0 \mathrm{mg} \mathrm{L}^{-1}+2,0 \mathrm{mg} \mathrm{L}^{-1} \mathrm{de}$ BAP e as maiores matéria seca foram obtidos com 1,0 $\mathrm{mg} \mathrm{L}^{-1}$ de AIB e também por 2,0 $\mathrm{mg} \mathrm{L}^{-1}$ de ANA e de AIB.

\section{- Testes fitoquímicos}

Dentre os constituintes analisados verificouse apenas a presença de heterosídeos cardiotônicos em calos de Cissus sicyoides L., em todos os tratamentos utilizados, sendo posteriormente evidenciada a presença desses metabólitos, mediante a triagem fitoquímica.
É importante salientar a dificuldade para comparar o teor de determinado metabólito produzido a partir de células e/ou tecidos in vitro com teores produzidos nos tecidos de plantas completas. Calos de Gomphrena globosa (Amaranthaceae) possuem potencial para a produção de vários metabólitos in vitro, inclusive compostos não observados na planta matriz (Andre et al., 2003). É possível que a expressão diferencial de genes seja responsável por esta variação de respostas.

Para a espécie em questão, faz-se necessário a realização de estudos mais aprofundados, visto que, até o presente momento não foram encontrados relatos na literatura sobre a presença de heterosídeos cardiotônicos em plantas de Cissus sicyoides L. Conclui-se que, para a calogênese de Cissus sicyoides L., a partir de segmento foliar faz-se necessário a adição de 6,0 $\mathrm{mg} \mathrm{L}^{-1}$ de BAP ao meio 


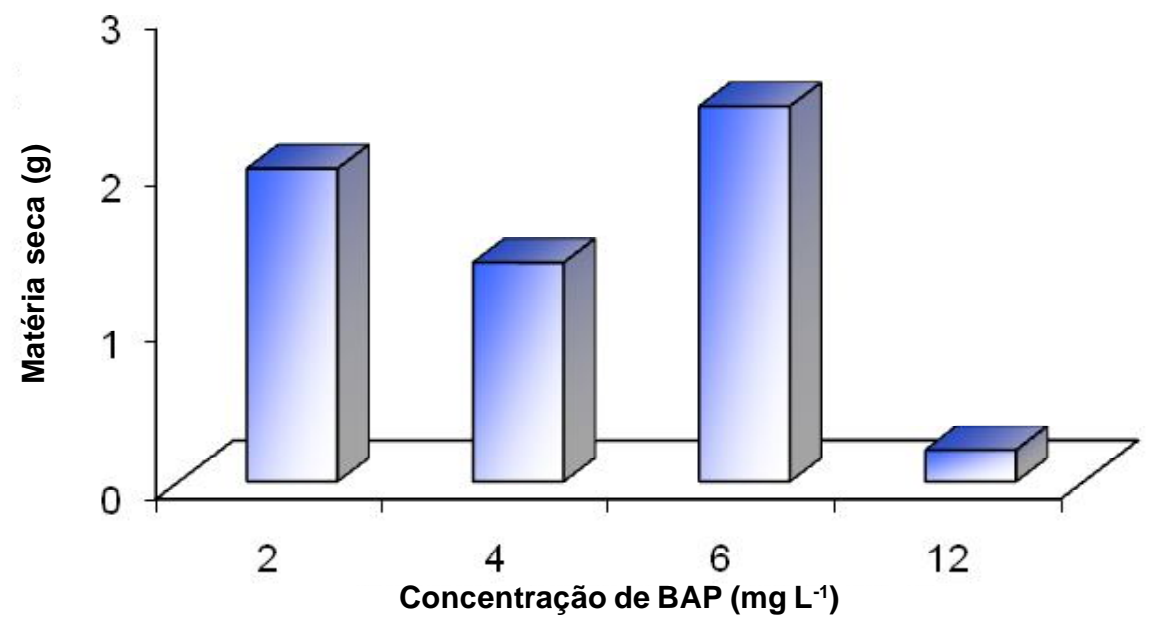

FIGURA 9. Matéria seca dos calos formados a partir de segmentos foliares de Cissus sicyoides $\mathrm{L}$. em função de concentrações de BAP. Barras seguidas da mesma letra nas barras não diferem significativamente (Tukey 0,05$)$.

de cultura e realizando-se dois subcultivos, após o cultivo in vitro. Identificou-se a presença de heterosídeos cardiotônicos em calos de Cissus sicyoides L.

\section{REFERÊNCIA}

ARIKAT, N.A. Micropropagation and accumulation of essencial oils in wild sage (Salvia fruticulosa Mill.). Scientia Horticulturae, v.100, p.93-202, 2004.

ANDRE, A.C.G.M. et al. Estudo comparativo da produção de metabólitos secundários em cultura de células e na planta in natura de Gomphrena globosa (Amaranthaceae). Revista Brasileira de Farmacognosia, v.13, p.22-4, 2003.

BARBOSA-FILHO, J.M. et al. Natural products inhibitors of the enzyme acetylcholinesterase. Revista Brasileira de Farmacognosia, v.16, p.258-85, 2006.

BARBOSA, W.L.R. et al. Flavonóides de Cissus verticillata e a atividade hipoglicemiante do chá de suas folhas. Revista Brasileira de Farmacognosia, v.12, p.13-5, 2002. BARCELÓ-MUÑOZ, A. et al. Micropropagation of adult avocado. Plant Cell Tissue Organ Culture, v.58, p.11-7, 1999.

BOTTA, B. et al. Cultura de tecidos vegetais: doze anos de experiência. In: YUNES, R.A.; CALIXTO, J.B. Plantas medicinais sob a ótica da moderna química medicinal. Chapecó: Argos, 2001, p.354-79.

CERQUEIRA, E.S. et al. Indução de calos em erva-detouro (Tridax procumbens L.) utilizando diferentes reguladores de crescimento e tipos de explantes. Ciência e Agrotecnologia, v.26, n.2, p.301-8, 2002.

CERQUEIRA, E.S. Propagação e calogênese in vitro em erva-de-touro (Tridax procumbens L.), uma planta medicinal. 1999. 81p. Dissertação (Mestrado em Fisiologia Vegetal) - Universidade Federal de Lavras, Lavras.

CORDEIRO, I.M.C.C. et al. Efeito de BAP sobre a proliferação de brotos in vitro de Schizolobium amazonicum Huber ex Ducke (paricá). Cerne, v.10, n.1, p.118-24, 2004. COSTA A.S. et al. Estabelecimento de alecrim-pimenta in vitro. Horticultura Brasileira, v.25, n.1, p.68-72, 2007. FLORES, R. et al. Otimização da micropropagação de Pfaffia tuberosa (Spreng.) Hicken. Ciência Rural, v.36, n.3, p.845-51, 2006.

KAYIM, M. et al. The effects of some carbohydrates on growth and somatic embryogenesis in citrus callus culture. Scientia Horticulturae, v.109, p.29-34, 2006.

LAMEIRA, O.A. Propagação in vitro e in vivo, dinâmica de crescimento de células, nutrição e identificação de flavonóides em erva-baleeira (Cordia verbenacea L.).1997. 87p. Tese (Doutorado em Fitotecnia) Universidade Federal de Lavras, Lavras.

MURASHIGE, T.; TUCKER, D. P. H. Grow factor requeriment of Citrus tissue culture. Proceedings of the First International Citrus Simposium, v. 3, p.1155-669, 1969. MURTHY, K.N.C. et al. Antioxidant and antimicrobial activity of Cissus quadrangularis L. Journal of Medicinal Food, v.6, p.99-105, 2003.

NOGUEIRA, R.C. et al. Indução de calos em explantes foliares de murici-pequeno (Byrsonima intermedia $A$. Juss.). Ciência e Agrotecnologia, v.31, n.2, p.366-70, 2007. $\mathrm{RAO}, \mathrm{S}$. et al. Plant cell cultures: chemical factories of secondary metabolites. Biotecnology Advances, v.20, p.101-53, 2002.

SANTOS, M.R.A. Germinação, calogênese e caracterização e saponinas em Smilax japecanga Grisebach. 1998. 81p. Dissertação (Mestrado em Fitotecnia) - Universidade Federal de Lavras, Lavras.

SILVA, G.A. Caracterização e padronização farmacológica da droga e extrato fluído de Cissus sycioides L. 1995. 98p. Tese (Doutorado) - Universidade Estadual de São Paulo, São Paulo.

SILVA, L. et al. Biciclogermacreno, resveratrol e atividade antifúngica em extratos de folhas de Cissus verticillata $\mathrm{L}$. Nicolson \& Jarvis (Vitaceae). Revista Brasileira de Farmacognosia, v.17, p.361-7, 2007.

SIMÕES, C.O. et al. Farmacognosia da planta ao medicamento. 5.ed. Porto Alegre/Florianópolis: Ed. Universidade/UFRGS/Ed. da UFSC, 2004. 821p. 